\title{
ARTICULATIONS ON VISUAL ETHNOGRAPHIC APPROACH FOR A SCIENCE READER OF SECONDARY SCHOOL
}

\author{
Neena Thomas \\ Asst.Prof. M. Ed. Department, Mar Theophilus Training College, Thiruvananthapuram, India. \\ K.Y. Benedict \\ Principal, Mar Theophilus Training College, Thiruvananthapuram, India.
}

\begin{abstract}
India as a land of rich heritage and history, its essence was not at all considered in our school system. Its embodiment is covered in the history textbook with the world history. We have to uncover the truth that our heritage is commendable in its genuine value. It is now imperative that we examine the possibility to assess the utility of social events and its memories in the process of understanding the worth of scientific concepts. These memories about various events will be more inspiring if it will be conveyed through visuals. Then the work will become impressionistic and reflective since a certain amount of objectivity can be perceived. So the investigator is discussing the major inadequacies of the contemporary Physical Science Reader in generating and maintaining scientific interest among secondary school students and the modifications to be incorporated to the contemporary Physical Science Reader. The method was the Focus Group Discussion conducted by the investigator with twelve participants. The members of the focus group were discussed and suggested a Visual Ethnographic Science Reader for Secondary School. The Visual Ethnographic Approach can support the learning process with historical facts, visual based cultural activities, enriched content and more effective Assessment technique. So the students will inculcate a habit of finding science in anything and everything around him. This helps him in the process of knowledge formulation.
\end{abstract}

\section{KEYWORDS: VISUAL ETHNOGRAPHIC APPROACH, SCIENCE READER, SECONDARY} SCHOOL

\section{INTRODUCTION}

In 1791 William Robertson, from Edinburgh University, Scotland reflects on "the knowledge which the Ancients had of India " explains, based on the classical texts by Arrian, Strabo, Ptolemy, Pliny, that the manners, customs, religions and many valuable productions of science and art that characterised contemporary Indian culture. Even if modern scholars question the reliability of these books, the possibility of these memories has to be reshaped and carved and these hints can open up a range of new areas of inquiry for students in science learning.

Over the last few decades, scholars have been arguing that memories are not direct routes to lived experience, but artifacts of a complex process which were existed once a while. But these memories give a soothing and enriching experience in everyone's life. It should be insisted that memory itself is amenable to scientific inquiry. Many of the best products in science have emerged as technologies that construct specific memories in particular social and cultural contexts. There is now a large possibility of the ways social groups construct memories, beliefs, legends and discourses for specific purposes and the mechanisms for perpetuating these events across areas. It is now imperative that we examine the possibility to assess the utility of social events and its memories for the process of understanding the worth of scientific concepts. These memories about various events will be more inspiring if it will be conveyed through visuals. Then 
the work will become impressionistic and reflective since certain amount of objectivity can be perceived. Another area emerging through visuals and ethnographic works is the indigenous knowledge, natural resource management and development. So there is a scope of these factors also in a visual ethnographic reader. Contextualization of our curriculum through the science reader is also possible here. It was found that the events and visuals specified have an important role for effective utilisation of the reader productively.

Therefore a few pertinent questions to be answered are:

1. What are the major inadequacies of the contemporary Physical Science Reader in generating and maintaining scientific interest among secondary school students?

2. How does activity oriented method enhance science learning among students?

3. What are the modifications to be incorporated to the contemporary Physical Science Reader?

4. What is the role of cultural practices and historical facts in a physical Science Reader?

Discuss the scope of incorporating historical facts, cultural elements, science concepts and visuals effectively in science reader?

\section{OBJECTIVES}

In view of the questions above, this paper is designed based on the following objectives:

1. To identify problems that the contemporary physical Science reader faces in order to suit the needs of the society and cultural significance of our country.

2. To examine the linking of classroom processes with the community to close the gap between textual knowledge and real life knowledge.

This paper is an attempt to describe various issues relating to physical science reader through discussion. Many issues that are analysed in the paper are based on the observations by educational experts. Some of the issues are interpreted with thorough discussion between other trainers in the field.

\section{METHOD}

DISHITA, the Focus Group Discussion conducted by the investigator with twelve participants for drawing out the scope of visual Ethnographic Approach in a scientific paradigm.

The expert gave a brief description to the group of the present difficulties of the content and the importance of Visual Ethnographic Approach. Then the investigator presented the attributes of Visual Ethnographic Approach and how this could be incorporated in the learning teaching process with an example.

The members of the focus group were discussed in the areas and presented their ideas relating to Science Reader of Secondary School.

\section{THINKING ABOUT PRESENT SCENARIO}

Despite their centrality to the scientific concepts, examples mention with each of it are not specific and precise. Those few who study the subject generally focusing the content, alien to the indigenous culture that is social focus and forte, will not remain in the mind of the learner for a long period and still the teacher overlook its importance. As well, teachers in science should be the indicators of originality and creativity and they never connect scientific theories with real experience. Consequently the decision making ability of the student might represent the clearest markers for tracing the more diffused skills like Contextual Learning, Scientific Thinking, Enculturisation, Collaboration and Updated Knowledge all will be ruled out. As Viji, Researcher from university of Kerala points out, "the content of the reader is incapable to make any significant difference in the decision making in students". The learners will remain the products of a generalised formal pattern. Complicating this organisation refers also to the lack of the references, extra work, pictures with captions, appreciation towards scientists, ethical as well as environmental issues. Even if the reader enhances observation, classification, analysis, it ignores creativity, imagination and high order 
thinking skills. Moreover, Science reader is seeking out elusive elements of continuity, to distrust arbitrary topic compartmentalisation and to constantly re-examine and revise.

\section{ACTIVITY ENHANCES LEARNING}

It has been traditionally assumed that activity arouses curiosity in children and encourages 'learning to learn' skills. If a student learns deriving benefit from an activity, then they are depicted as engaged, thought -provoked, discovery learning enabled, identifying the earned knowledge, ensuring participation and self involvement, tends for cooperate learning. Above all, develops a positive attitude towards science. Activity refers to both mental and physical; both inside the class and outside the class .Close observation reveals that these scheduled activities are awkward to be exposed to any cultural essence. Here visual activity can have a significant role. These programs can foster their competence has received much attention throughout the Educational process. Importance has to be attached to the distinct influences that promote the freedoms that the participants have, including their ability to make use of their higher order thinking skills. Researcher Indu Pillai from university of Kerala noted, "When we present visual activity, Teacher skill Enhancement Programme to be introduced." This program can also be instigated to increase the teaching efficiency among secondary school teachers.

\section{SYNCHRONIZED CONTENT}

The stability of knowledge lies when it correlates theory and experience. One of the central questions for this paper is how far the strategic shift marks a genuine change in Science Reader, rather than rhetoric. The main argument proposed is that the learners shifts are real so far that it signifies that they are not even open the daily newspaper or listen to the latest news or hear about science-related issues. Still now they are depending on outer sources for their gratification of learning needs, even if many resources are available for them to extract the required elements to add to the core idea based on their own objective inferences. However, it most accurately ensures that originality can be realized through specificity. For that reader must give options for long term, medium term and short term knowledge acquisition methods. The teacher must stress the need to learn, while the ostensible shift in content resulting in not only accepted facts but also the argued facts to be included. The presentation of the reader must be attractive with captions for pictures, important points are noted, an activity which is possible to be included, provisions for reference must be included. The questioning part should be reframed. The reader must be utilizable for learner, teachers and society. For that Dr. Sindhya, Professor from University of Kerala says "the contents to be included under the headings VITAL, ESSENTIAL and DESIRABLE." For assessment, triangulation technique can be used to ensure both quantity and quality of the content. Above all the relation between objective and achievement has to be confirmed.

\section{PLANNING TO LOCALISE THE GLOBALISED CONTENT}

Dr. Abraham George, Dept. of Chemistry, Mar Ivanios College, Thiruvananthapuram mentioned, "We have to build up a culture of interest in science which enables students to cope up with a future which depends on science and technology." The presence of scientific principles and cultural practices can be highlighted in order to build up a culture of interest in science. The importance of science is its substantive contribution in social life. But here too, rhetoric gaining of scientific knowledge seems to be playing against learners' ambition of strengthening their future by connecting to the universal markets. Our science readers must express reality as well as reflexivity which can arouse an aesthetic sense among learners. India can march ahead of any other country by operationalising its culture, which is not only past but it is futuristic too-both philosophical and interdisciplinary in nature. Visuals help to entertain students and to make them aware of our culture and history. It is to be noted that doubts on the historical relevance of science is not a reason for not institutionalising a mechanism for its effective inclusion.

\section{CULTURE AND SCIENCE}

Three important criteria for judging the performance of a reader for educational relevance would be the extent of community participation that can be ensured, equity in incorporating cultural elements, science concepts and visuals effectively and efficiently in regenerating the knowledge as it demands. On all these 
counts, contemporary reader that looks effective may be found lacking from a logical perspective. In terms of immediate regeneration, many of the initiatives have to take to strengthen the existing system. It can be done by lining cultural spaces to be identified and it should be incorporated. It helps in methodology building in a new dimension by providing interdisciplinary understanding. As V. Reghu, Former Dean of School of Youth Studies, RGNIYD says, "VESR enables the student to take action, to voice their opinion and to participate in decision making process". Visual learners are satisfied here by developing curiosity and provide a powerful impact on culture. Here we are framing science harmoniously. Humanistic presentation is possible and learners can overcome many scientific and social issues existing today based on the cultural view. It enables the student to take action, to voice their opinion and to participate in the decision making process. It provides a good example of how conflicts and controversy can enhance an appreciation towards the nature of science. The relation between science and culture are in the form of plug points as connectors. And it happens instead of evaluation, feedback can be instigated. State wise use of text without any chance for flexibility by the handling teacher will be crumbled and then the experiential learning situation can be created. The innovative ideas of the teacher play an important role in creating inspiring situations. Majority think that science, culture and history are three different streams and that they have no connection. But when they are together they can cause magnificent changes and the way they are being explained should be taken care of.

\section{VISUAL ETHNOGRAPHIC SCIENCE READER (VESR) IN SECONARY SCHOOL}

India does possess some special cultural and historical characteristics which may have helped its social transformation. But our educational system really avoided these cultural aspects, supplementing or supplanting our inheritance. Our science reader can be modified by inculcating these cultural aspects in its core content. VESR is patterned in the following system. Before entering to the unit each participant has to check their prerequisite knowledge. The unit provides an event from culture ethnographically followed by certain questions based higher-order-thinking. There some analogies are given to the participants. It encloses an individual activity. Field visuals are also enclosed. An Inference board with the concise summary of the unit are included. Historical Explanation relating to the sub theme was also exposed. QR code was given so that Participant can reach a site explaining the concept in depth. Leading questions can direct the participant to the following unit. Reflection exercise is given for each unit so that each participant can assess themselves about their level of performance.

If the preceptor (teacher) maintaining a class using Visual Ethnographic Reader, the participant (learner) will through Visual Ethnographic Approach. The Visual Ethnographic Approach can support the learning process with historical facts, visual based cultural activities, enriched content and more effective Assessment technique. So the students will inculcate a habit of finding science in anything and everything around him. This helps him in the process of knowledge formulation.

\section{EMERGING FACTS}

The significant answers to the questions imply:

i. The contemporary Physical Science Reader is not successful in incorporating contextual, collaborative, activity-oriented, consequential way of presentation which can generate and maintain scientific interest among secondary school students.

ii. In Activity oriented method Activity means both mental and physical, both inside the class and outside the class. But in reader it is the redrafting of what was there already in a decorative style. When we examine, we can see the cultural essence is missing.

iii. We can modify the contemporary Physical Science Reader with historical facts, cultural activities, enriched content, and more effective Assessment technique.

iv. The cultural practices and historical facts in a physical Science Reader helps to harmonise science by using plug points as connectors between science, visuals, culture and history.

v. The scope of VESR can be explained in two ways

a) What we saw and heard-the concrete experience of science.

b) What we thought and how we feel-the perceived concept of science. 
In short, VESR expresses Reality, Reflexivity and set up a culture of science among students.

\section{CONCLUSION}

This study closes on the last that the Visual Ethnographic Approach reflects the scientific curiosity and aesthetic aspirations of a new affluent and tentatively confident Indian student. The visual regime of this cosmopolitan imagination flaunts the notion that it is possible to distinguish oneself from others by putting on display and thus shaping a multi-ethnic environments, or at least the idea of what it could be like. The visuals discussed in the learning process are imbued with the desire to "belong to class", to be world class, and for control over the allegedly disorderly, uncontrollable public. Yet, possibly the visual of the science as an art ,despite the lures of experiments, theories and equations is one within limiting and artificial boundaries, shaping, as possible rightly noted, a "learn science with a new style."

\section{ACKNOWLEDGEMENTS}

This research was guided by Dr. K.Y. Benedict and the venue of Focus Group Discussion was' Mar Theophilus Training College, Thiruvananthapuram, Kerala.

\section{BIBLIOGRAPHY}

1. Best, John W., Kahn, James V.(1996).Research in Education, New Delhi:Prentice Hall of India Pvt. Ltd.

2. Bloor, M., Frankland, J., Thomas, M., \& Robson, K. (2001). Focus groups in social research. Thousand Oaks, CA: Sage.

3. Brajendranath Seal. (1915). The Positive Sciences of the Ancient Hindus. London: Longmans, Green and Company.

4. Bruce L. Berg. (2008).Visual Ethnography. The Sage Encyclopedia of Qualitative

5. Creswell, John. (2009). Research Design. Qualitative, Quantitative and Mixed

Methods Approaches. New Delhi: Sage Publications

6. Pink. (2005). "Doing Visual Ethnography". USA: SAGE Publications Ltd..

7. Poltorak M. (2015). Project in Visual Anthropology. Canterbury: University Of Kent. 